\title{
The contribution of noradrenergic nerves to the vasoconstrictor response during local cooling of leg and forearm skin in humans
}

\author{
Ramzi A. Al-horani ${ }^{1}$ and Mukhallad Mohammad ${ }^{2}$ \\ ${ }^{1}$ Department of Exercise Science, Yarmouk University, Irbid, Jordan \\ ${ }^{2}$ Department of Physiology, Medical school, Jordan University of Science and Technology, Irbid, Jordan
}

\begin{abstract}
This study investigated the noradrenergic contribution during the cutaneous vasoconstrictor response to local cooling in the leg and forearm. On each limb, one site was perfused with Yoh/Prop to block the postsynaptic adrenoceptors and another with Lactated Ringer's (control) using microdialysis. Blood flow was measured by Laser-Doppler flowmetry (LDF). Cutaneous vascular conductance (CVC) was calculated as LDF units divided by the mean arterial pressure. After baseline measures, skin was locally cooled to $24^{\circ} \mathrm{C}$. Basal CVC was similar at all sites in the leg and forearm (all $p>0.1$ ). During the first $10 \mathrm{~min}$ of local cooling, CVC was reduced in the leg $(p<0.005)$ and unchanged in the forearm control sites $(p=0.2)$. Yoh/Prop induced an increased CVC in the leg and forearm to a similar level $(39.2 \pm 11.5$, and $41.3 \pm 3.3 \% \mathrm{CVC}$, respectively; $p<0.35)$. Late during local cooling, the vasoconstriction was attenuated in the leg and forearm at Yoh/Prop (-38.2 $\pm 5.3-37.1 \pm 5.3 \% \mathrm{CVC}$, respectively; $p=0.5)$ compared to control sites $(-69.1 \pm 5.8 v s .-54.5 \pm 6.4 \% \mathrm{CVC}$, respectively; $p<$ $0.005)$. Noradrenergic contribution was greater in the leg than the forearm during the late vasoconstrictor response $(p=0.006)$. These data indicate that the leg skin can induce greater vasoconstriction than forearm during local cooling, possibly via higher noradrenergic sensitivity in the leg skin.
\end{abstract}

Key words: Local cooling - Noradrenergic activity — Vasoconstrictor response — Skin blood flow - Autonomic - Cutaneous vascular conductance

\section{Introduction}

Mechanisms underlying changes in skin blood flow (SkBF) in response to local temperature alterations have been examined primarily on the forearm skin (Johnson et al. 2014). However, it has been shown that skin is markedly heterogeneous in terms of SkBF, in which not all body regions exhibit similar basal and maximal SkBF (Hertzman and Randall 1948). A series of studies examining the mechanisms of elevated SkBF in the leg and forearm during local heating has suggested that the distinct regional contributions of sympathetic nerves, sensory nerves, and nitric oxide synthase (NOS) activities result in different SkBF pattern in both limbs (Del Pozzi et al. 2013; Del Pozzi and Hodges 2015; Hodges et al. 2015).

Correspondence to: Ramzi A. Al-horani, Department of Exercise Science, Yarmouk University, Irbid, Jordan

E-mail: raalhorani@yu.edu.jo
In regard to local skin cooling, the resulted vasoconstrictor response is composed of a rapid short and a prolonged sustained cooling phase (Johnson et al. 2005; Yamazaki et al. 2006b; Hodges and Johnson 2009). The role of the noradrenergic nerves in the vasoconstrictor response to local cooling has been established primarily from arm data (Hodges and Johnson 2009; Johnson et al. 2014). Their role has been suggested based on the observed transient vasodilation and the attenuated vasoconstriction early and late during local cooling, respectively, when the noradrenergic function was blocked; either presynaptically through bretylium tosylate (BT) or post-synaptically through yohimbine and propranolol perfusion (Pérgola et al. 1993; Johnson et al. 2005; Yamazaki et al. 2006b). Indeed, local cooling was shown to decrease the synthesis and release of noradrenaline (Boels et al. 1985) rather than increasing its concentration in the synaptic cleft. To compensate the decreased neurotransmitters release, local cooling induces an increased post-synaptic expression and translocation of $\alpha_{2} C^{-a d r e n e r g i c ~ r e c e p t o r s ~(C h o t a n i ~ e t ~ a l . ~ 2000, ~}$ 2004; Bailey et al. 2004; Johnson et al. 2014). 
Since noradrenergic contribution was found different in the leg and forearm in the vasodilator response to skin local heating (Del Pozzi and Hodges 2015), it is plausible that the noradrenergic nerves contribute differently between body regions in the vasoconstrictor response to skin local cooling; yet this has not been completely investigated. Nonetheless, in one study, the vasoconstrictor responses in the forearm and calf were examined during local cooling with and without oral ingestion of ascorbic acid (Yamazaki 2012). Local cooling induced $\sim 50 \%$ reduction in cutaneous vascular conductance (CVC) and 53\% without ascorbic acid ingestion, while CVC was reduced $\sim 58 \%$ and $\sim 66 \%$ with ascorbic acid ingestion in the forearm and leg, respectively. These results have shown no to minimal difference in the CVC between the forearm and leg during local skin cooling; however, the regional responses were not statistically compared. In addition, Yamazaki (2012) maintained the skin temperature at $24^{\circ} \mathrm{C}$ for $20 \mathrm{~min}$, while others maintained the local temperature at $24^{\circ} \mathrm{C}$ for $30-42.5 \mathrm{~min}$, given the maximum vasoconstriction was selected within the last 3-5 min of the local cooling period (Johnson et al. 2005; Yamazaki et al. 2006b). The regional vasoconstrictor response was also examined through administration of exogenous norepinephrine to the skin. This administration exhibited greater cutaneous vasoconstrictor response in the leg than in the forearm due to higher reactivity of $\alpha_{1^{-}}$, and $\alpha_{2}$-adrenoceptors (Yamazaki and Yuge 2011). Similarly, $\alpha_{1}$-adrenoceptors reactivity to adrenergic agonists with subsequent vasoconstriction was higher in the femoral relative to brachial artery (Pawelczyk and Levine 2002). Nevertheless, the role of the noradrenergic receptors in the regional vasoconstrictor response to local cooling has never been assessed. Taken together, these data have shown that the pattern of the vasoconstrictor response and the associated noradrenergic contribution during local skin cooling in the lower and upper body regions are still unclear and need to be elucidated.

Therefore, the aim of this study was to investigate the pattern of the cutaneous vasoconstrictor response to local cooling in the leg and forearm, and to examine the noradrenergic involvement in this regional response. Based on the previous observations that showed higher reactivity of adrenoceptors in lower body regions, we hypothesized that, in association with greater noradrenergic contribution, local cooling would induce greater vasoconstriction in the leg than in the arm.

\section{Materials and Methods}

\section{Participants}

Power analysis revealed that 6-8 participants were required on the basis of $\alpha$ of 0.05 and $\beta$ of 0.95 and on the expected mean and standard deviations from previous studies investigating the vasoconstrictor response to local cooling (Hodges et al. 2006, 2007b). Total of 10 healthy participants, 6 males and 4 females $(29 \pm 2$ years; body mass $=78.7 \pm 5.5 \mathrm{~kg}$; height $=174.4 \pm 6.7 \mathrm{~cm}$; body fat estimated from skinfolds $=$ $13.6 \pm 5.2 \%$ ), who were involved in physical activity at least 3 days per week for 30 min every day, were voluntarily recruited for the study. Selected participants were nonsmokers and not taking any medications that would influence the vascular function. After approval from the local ethical committee, participants signed informed consents explaining the procedures to be performed throughout the study.

The leg and arm testing were conducted in random order on two separate days rather than one day to reduce discomfort the participants previously reported from the long immobilization (Del Pozzi et al. 2013). Also, the dayto-day variation in $\mathrm{SkBF}$ responses seems unlikely for SkBF responses to different stimuli were found highly reproducible from day-to-day in healthy participants (Kubli et al. 2000). At each day, participants refrained from exercise for 24 hours, and from alcohol or caffeinated beverages 12 hours prior to the study, and were fast for at least 2 hours prior to the commencement of the study procedures. Participants were also asked to keep the same average energy intake and similar type of meal prior to every laboratory visit. Females were tested in two consecutive days during the early follicular phase, and were not taking oral contraceptives.

\section{Instrumentation}

All SkBF measures were performed at an ambient temperature of $22-24^{\circ} \mathrm{C}$. Laser-Doppler flowmetry (LDF) (MoorVMSLDF2, Moor instruments, Devon, UK) was used to measure the red blood cells flux as an index of SkBF (Oberg 1990), which enables continuous recording without altering the baseline on any region (Johnson 1990), and is not affected by the underlying skeletal muscle blood flow (Saumet et al. 1988). Laser-Doppler probes were integrated with custombuilt metal Peltier cooling/heating discs to form one unit that covered $\sim 7 \mathrm{~cm}^{2}$ of skin except a small opening in the center for the laser probe. Complete blockade of $\alpha$ - and $\beta$-adrenergic receptors was achieved through perfusion of a combination of yohimbine and propranolol (Yoh/Prop) at a concentration of $5 \mathrm{mM}$ and $1 \mathrm{mM}$, respectively, through intradermal microdialysis (Stephens et al. 2001; Hodges et al. 2008; Tew et al. 2011). This combination at these concentrations was shown to completely block the vascular response to exogenous norepinephrine (Stephens et al. 2001). The microdialysis probes were custom built, and each contained a $10 \mathrm{~mm}$ permeable membrane (regenerated cellulose, inner diameter $200 \mu \mathrm{m}, 18$ $\mathrm{kDa}$ nominal molecular mass cut-off) used for drug infusion, associated with polyimide tubing at each end (Carter and Hodges 2011; Del Pozzi et al. 2013; Del Pozzi and Hodges 2015). Insertion of microdialysis was preceded by local anesthesia through direct application of ice to the skin sites for 
5 min (Hodges et al. 2009b). A 22-gauge needle was inserted aseptically into the dermal layer for $\sim 2.5 \mathrm{~cm}$ at each site, and a probe was threaded through the lumen of the needle, leaving the probe at the site of measurement after removing the needle (Carter and Hodges 2011). There was a 90 min time lapse between the microdialysis placement and the beginning of measurements for fiber placement-induced trauma to subside (Hodges et al. 2009a). Baseline SkBF measures were recorded at the local skin temperature $\left(\mathrm{T}_{\text {loc }}\right)$ of $34^{\circ} \mathrm{C}$ at the sites of the LDF probes. Mean arterial pressure (MAP) was calculated every $5 \mathrm{~min}$ on the contralateral arm via oscillometry $((2 \times$ diastolic pressure + systolic blood pressure)/3). There were no expected differences in the MAP results whether blood pressure was measured on the leg or the arm because a previous study has shown similar systolic, diastolic, and mean pressures measurements on the brachial and femoral arteries in the supine position (Park and Guntheroth 1970).

\section{Protocol}

The following procedures were similarly conducted on the leg and forearm. All procedures were performed while subjects were in the supine position and upper and lower limbs were at the level of the heart, attempting to prevent mixing the effects of precooling with venoarteriolar response (Crandall et al. 2002). A Yoh/Prop-treatment site and an untreated control site (Ringer's, study vehicle) were selected on the ventral aspect of the forearm and the lateral aspect of the lower leg. A period of $90 \mathrm{~min}$ was allowed for the needle insertion trauma to subside following microdialysis probes placement. Data collection then started using LDF probes. For the next $20 \mathrm{~min}$, both sites were perfused with lactated Ringer's solution at a rate of $4 \mu \mathrm{l} / \mathrm{min}$ to obtaining baseline measures. The treated site was then perfused with Yoh/Prop solution for $60 \mathrm{~min}$ at a rate of $4 \mu \mathrm{l} / \mathrm{min}$ (Johnson et al. 2005), while the control site remained continually perfused with lactated Ringer. At the end of drug infusion, participants were applied to cold pressor test by immersing the contralateral arm in iced water $\left(\sim 2^{\circ} \mathrm{C}\right)$ for an uninterrupted 3-min to verify a complete noradrenergic blockade at the treated skin sites. The Noradrenergic blockade was taken incomplete if the test resulted in reduced CVC > 10\% (Hodges et al. 2007b; Del Pozzi and Hodges 2015); however, the condition of blockade failure was not observed among the participants. $\mathrm{T}_{\text {loc }}$ on both sites was then raised and stabilized at $34^{\circ} \mathrm{C}$ for 10 min during which baseline data was recorded. $\mathrm{T}_{\text {loc }}$ was then reduced to $24^{\circ} \mathrm{C}$ at a rate of $-1^{\circ} \mathrm{C} /$ min and maintained for another $30 \mathrm{~min}$ until the blood flux measurement stabilized (Pérgola et al. 1993; Johnson et al. 2005). After local cooling was finished, $\mathrm{T}_{\text {loc }}$ was recovered to $34^{\circ} \mathrm{C}$, and cold stress was applied again on the contralateral arm to ensure the adrenergic receptor blockade was still effective at the Yoh/Prop-treated sites.

\section{Data analysis}

Red blood cell flux was recorded at $50 \mathrm{~Hz}$ and stored electronically offline for future analysis (Biopac MP150, Camino Goleta, CA). LDF recording was continuous throughout the study time and averaged for 20 -s periods, and then compiled into 1-min averages. SkBF was presented as CVC and was calculated by dividing LDF by MAP to eliminate any MAP alterations that occurred during data collection. CVC was normalized to baseline and expressed as the percentage change from baseline (\%CVC). CVC was analyzed during the first $10 \mathrm{~min}$ of local cooling denoting the early phase, and at the final $5 \mathrm{~min}$ denoting the late phase. The average of $1 \mathrm{~min}$ around the peak of the selected areas was taken as the representative piece of data for that particular phase. All data are presented as mean \pm standard deviation. The percentage of noradrenergic contribution in the late vasoconstrictor response relative to the maximum vasoconstriction achieved in untreated sites was calculated as follows:

$$
\begin{aligned}
& {\left[\left(\% \mathrm{CVC}_{\text {baseline Control }}-\% \mathrm{CVC}_{\text {baseline Yoh/Prop }}\right) /\right.} \\
& \left./ \% \mathrm{CVC}_{\text {baseline Control }}\right] \times 100
\end{aligned}
$$

A two-way repeated measures ANOVA was utilized to evaluate the effect of treatment (Yoh/Prop vs. Lactated Ringer's) and limb (arm vs. leg) on the basal CVC and \%CVC in the early and late local cooling phases with the Bonferroni correction for multiple comparisons when appropriate. When applicable, a paired t-test was used to compare between the corresponding sites. Data for males and females were analyzed together for the indistinguishable difference between genders and for the small power to run statistical comparisons. Significance was set at $p<0.05$.

\section{Results}

Figure 1 shows the SkBF tracing responses from one representative subject during the early and late phases of local cooling in the forearm and leg at control and Yoh/Proptreated sites. Note, that only the Yoh/Prop-treated sites in forearm and leg exhibited an initial vasodilation while it was absent at control sites. Late during local cooling all sites demonstrated reduction in SkBF, which was attenuated with Yoh/Prop treatment in the leg and forearm skin.

CVC was not different at control and Yoh/Prop-treated sites in the forearm $(0.26 \pm 0.07 v s .0 .27 \pm 0.06 \mathrm{U} / \mathrm{mmHg}$, respectively; $p=0.3)$ and leg $(0.27 \pm 0.05$ vs. $0.28 \pm 0.06 \mathrm{U} /$ $\mathrm{mmHg}$, respectively; $p=0.2$ ). Infusion of Yoh/Prop solution increased the basal CVC to $0.32 \pm 0.07(p=0.001)$, and to $0.31 \pm 0.06 \mathrm{U} / \mathrm{mmHg}(p=0.01)$ in the forearm and leg, respectively. Basal CVC values were similar between the corresponding Yoh/Prop-treated and control sites in the 


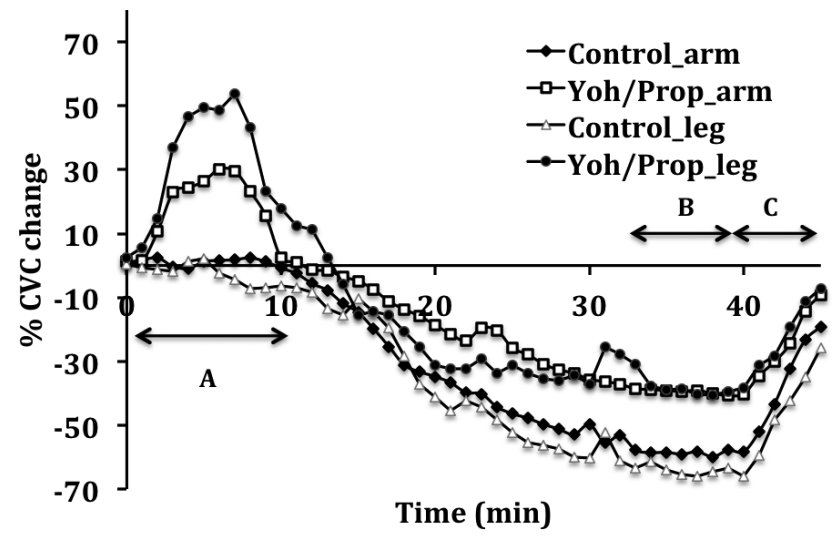

Figure 1. Cutaneous vascular conductance (CVC) change from baseline (\%CVC) obtained from one representative subject during local cooling at rate of $-1^{\circ} \mathrm{C} / \mathrm{min}$ from $34^{\circ} \mathrm{C}$ to $24^{\circ} \mathrm{C}$. There were 2 sites selected on the arm and 2 on the leg, one site was perfused with lactated Ringer as control, and the other with yohimbine/ propronalol (Yoh/Prop). The early response was obtained during the first $10 \mathrm{~min}$ of local cooling (A). The late response was obtained during the last $5 \mathrm{~min}$ of local cooling (B). After local cooling was finished, skin sites were reheated to $34^{\circ} \mathrm{C}(\mathbf{C})$.

forearm and leg before and after drug infusions $(p>0.05$ for all comparisons).

\section{Early local cooling}

Figure 2 illustrates the average change in CVC responses from 10 participants during the early $10 \mathrm{~min}$ of local cool- ing at the control and Yoh/Prop-treated sites in the forearm and leg. Yoh/Prop treatment significantly altered the early vasoconstrictor response to local cooling $(p<0.005)$. Relative to baseline, early local cooling induced a reduction in CVC $(-5.6 \pm 3.3 \%$ CVC; $p<0.005)$ at the control sites in the leg, but not in forearm control sites $(1.6 \pm 3.6 \% \mathrm{CVC} ; p=$ 0.2 ). With Yoh/Prop treatment, early vasoconstriction was reversed in the forearm to $39.2 \pm 11.5 \% \mathrm{CVC}(p<0.005)$, and in the leg to $41.3 \pm 3.3 \% \mathrm{CVC}(p<0.005)$. CVC change at the control skin sites was significantly different between the leg and forearm $(p=0.002)$. The transient vasodilation at Yoh/Prop-treated sites was not different between the leg and forearm skin sites ( $p=0.35$ ) (Fig. 2).

\section{Late local cooling}

Late phase was selected during the last $5 \mathrm{~min}$ of local cooling at which CVC was stabilized for $30 \mathrm{~min}$ at $24^{\circ} \mathrm{C}$. A progressive reduction in CVC was accompanied along with the continuous decreasing local skin temperature $\left(\mathrm{T}_{\text {loc }}\right)$. Vasoconstriction relative to baseline was evident at the control and Yoh/Prop-treated sites in the forearm $(-54.5 \pm 6.3$ and $-37.1 \pm 5.3 \% \mathrm{CVC}$, for control and Yoh/ Prop sites, respectively) and leg $(-69.1 \pm 5.8$ and $-38.2 \pm$ $5.3 \% \mathrm{CVC}$, for control and Yoh/Prop sites, respectively) ( $p<0.005$ for all sites relative to baseline). There was a significant effect of Yoh/Prop treatment $(p<0.005)$ on \%CVC responses late during local cooling through which Yoh/Prop treatment attenuated the vasoconstriction compared to control sites in both the forearm and leg $(p<0.005)$ (Fig. 3). In addition, there was a treatment

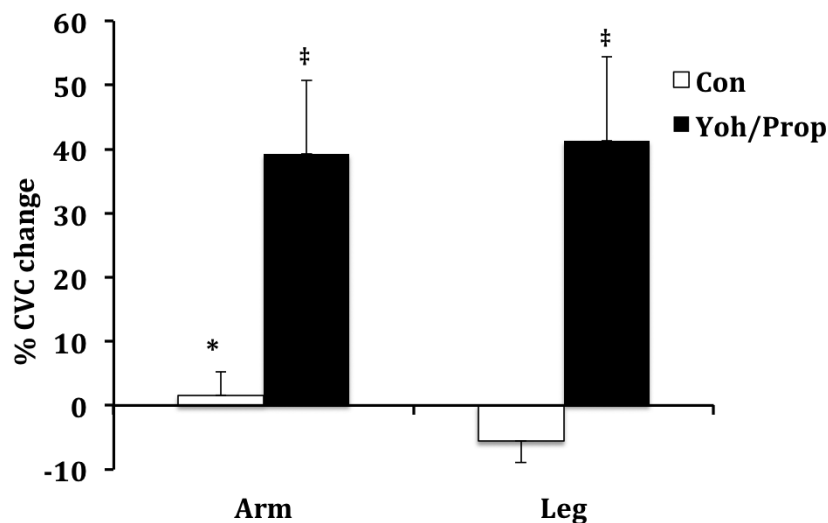

Figure 2. The change in cutaneous vascular conductance normalized to baseline (\%CVC) in the early phase of local cooling (first $10 \mathrm{~min}$ ) at control (Con) and yohimbine/propronalol-treated (Yoh/Prop) sites in arm and leg. Yoh/Prop administration induced a reversed vasodilation in both limbs. ${ }^{*}$ Different from the leg corresponding site at $p<0.05$; $\neq$ different from control site in the same limb at $p<0.05$.

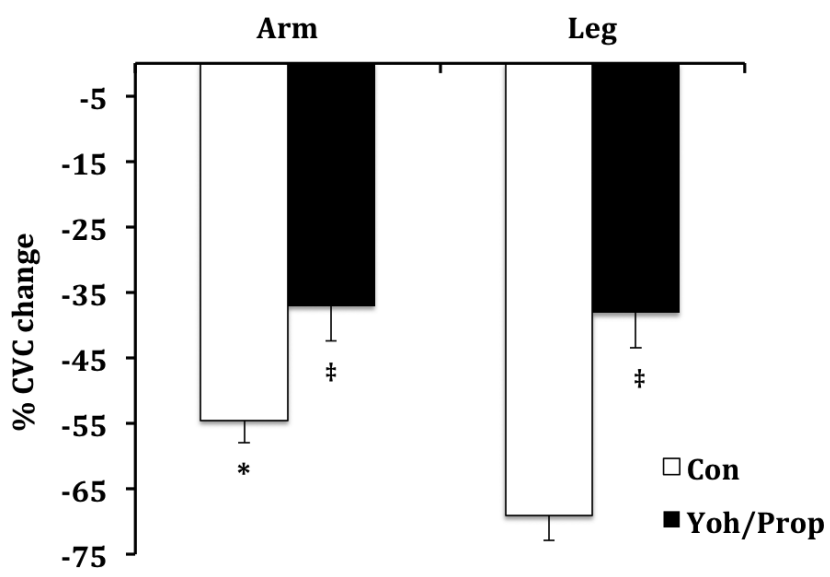

Figure 3. The change in cutaneous vascular conductance normalized to baseline (\%CVC) in the late phase of local cooling at control (Last $10 \mathrm{~min}$ ) (Con) and yohimbine/propronalol (Yoh/Prop) sites in arm and leg. Both limbs showed attenuation of vasoconstriction at Yoh/Prop-treated sites. ${ }^{*}$ Different from the leg corresponding site at $p<0.05$; $\ddagger$ different from control site in the same limb at $p<0.05$. 
$x$ limb interaction effect on \%CVC $(p=0.001)$. The leg demonstrated a greater vasoconstriction than the forearm at skin control sites $(p<0.005)$. However, at Yoh/Prop sites $\mathrm{CVC}$ was attenuated to a comparable level at the forearm and leg ( $p=0.5)$ (Fig. 3).

The percent noradrenergic contribution to late vasoconstrictor response was higher in the leg than in the forearm (44.8 \pm 5.5 vs. $31.2 \pm 11.9 \%$ CVC, respectively; $p=0.006$ ) (Fig. 4).

\section{Discussion}

We aimed to investigate the role of noradrenergic functions in the vasoconstrictor response to local cooling in the forearm and leg skin. Our findings have shown that the forearm and leg skin sites differ in the early and late vasoconstrictor responses and blockade of the postsynaptic adrenoceptors resulted in similar responses between the limbs. Our study was the first to investigate the contribution of noradrenergic receptors in the regional vasoconstrictor responses to skin local cooling. The preceding studies that have shown different contributions of sensory nerves, sympathetic and endothelial NOS in the regional SkBF responses were all conducted during the vasodilator responses to local heating (Del Pozzi et al. 2013; Del Pozzi and Hodges 2015; Hodges et al. 2015).

Early during local cooling it was unusual to observe no change in CVC at control sites in the forearm although previous studies have consistently shown reduced CVC early in the local cooling (Johnson et al. 2005; Hodges et al. 2006; Thompson-Torgerson et al. 2007). Similarly, forearm $\mathrm{CVC}$ was not reduced in response to local cooling at a rate of $-0.33^{\circ} \mathrm{C} / \mathrm{min}$ until $15-20 \mathrm{~min}$ of the cooling procedure (Yamazaki et al. 2006b; Hodges et al. 2007b). The blunted vasoconstriction was probably a role of the slow cooling rate compared to the higher rate used in the present and other studies $\left(-1\right.$ to $\left.-4^{\circ} \mathrm{C} / \mathrm{min}\right)$. Despite the same rate of cooling and concentrations of drugs used by the current study and the study of Johnson et al. (2005), the initial CVC at control sites was different between the two studies. The reasons for this discrepancy are unclear. Nonetheless, Johnson et al. (2005) did not report the body weight, body fat percentage, and the phase of the menstrual cycles during which the females were tested. These variables have been shown to influence the cutaneous blood flow responses (Charkoudian et al. 1999; Petrofsky et al. 2010). However, given the available data, comparisons regarding these variables are not applicable. In addition, this study left the skin site for $90 \mathrm{~min}$ for the instrumentation-induced trauma to subside, whereas Johnson et al (2005) allowed 2 hours. The needle insertion trauma has been shown to alter the cutaneous vascular responses to whole body heating (Hodges et al. 2009a), and it

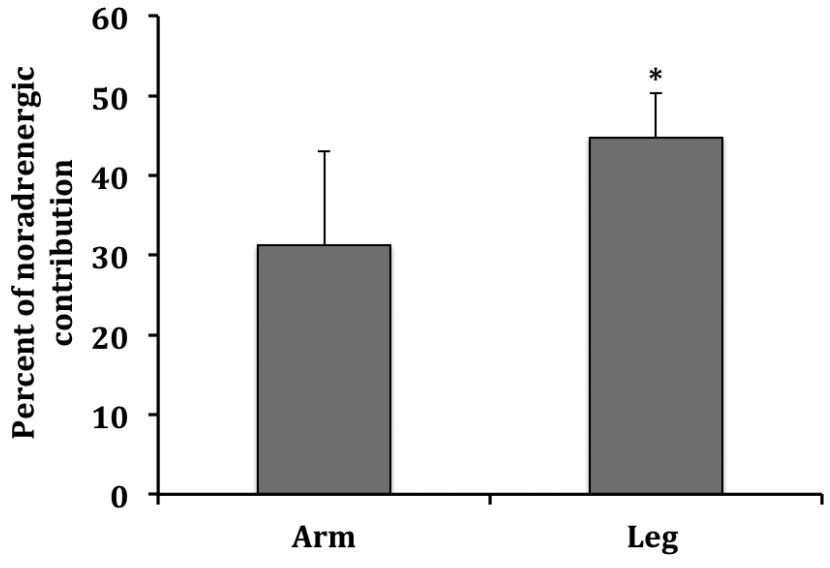

Figure 4. Percent noradrenergic contribution during the late vasoconstrictor response to local cooling in arm and leg skin sites. * Different from arm at $p<0.05$.

is possible to have an effect during local cooling. Yet, these propositions need to be elucidated.

The transient vasodilation that occurred during the early local cooling in the leg and forearm at the Yoh/Prop sites was also observed previously at skin sites treated with either Yoh/Prop or BT when locally cooled to $29^{\circ} \mathrm{C}$ at a similar rate used in the present study $\left(-1^{\circ} \mathrm{C} / \mathrm{min}\right)$, or to $24^{\circ} \mathrm{C}$ at higher rate $\left(-4^{\circ} \mathrm{C} / \mathrm{min}\right)$ (Johnson et al. 2005; Yamazaki et al. 2006b). This phenomenon was suggested to take place during rapid local cooling via increased blood flow to areas of arteriovenous anastomoses (Johnson et al. 2014). Despite the fact that Yoh/Prop treatment abolished the early CVC difference between the leg and forearm in the present protocol there is no strong evidence to attribute this initial regional CVC difference to stronger noradrenergic signals in the leg. This was likely because of two reasons. First, when using BT as another way of blocking the noradrenergic function the transient vasodilation was absent during a slower rate of local cooling $\left(-0.33^{\circ} \mathrm{C} / \mathrm{min}\right)$ (Yamazaki et al. 2006b; Hodges et al. 2007b). The second is that sensory nerves have been shown the predominant contributor in the early vasoconstrictor response to local cooling (Johnson et al. 2005; Yamazaki et al. 2006b; Hodges et al. 2007b). This was demonstrated through the resultant transient vasodilation during the early phase of local cooling at a rate of $-1^{\circ} \mathrm{C} / \mathrm{min}$ (Johnson et al. 2005) and at a slower rate of $-0.33^{\circ} \mathrm{C} / \mathrm{min}$ (Hodges et al. 2007b) at sites treated with the anesthetic EMLA cream. In addition, the magnitude of $\mathrm{CVC}$ change during the early phase of local cooling was greater at sites treated with EMLA cream compared to the sites treated with Yoh/Prop or BT. For example, local cooling at rate of $-0.33^{\circ} \mathrm{C} / \mathrm{min}$ increased CVC by $64 \%$ at EMLA-treated compared to $14 \%$ at BT-treated skin sites (Hodges et al. 2007a). Similarly, CVC was increased in the forearm by $\sim 212 \%$ with EMLA treatment compared to $20 \%$ 
with BT treatment and $25 \%$ at sites treated with Yoh/Prop early during local cooling at a rate of $-1{ }^{\circ} \mathrm{C} / \mathrm{min}$ (Johnson et al. 2005). Overall, those preceding observations indicate that sensory nerves might have a superior role to noradrenergic nerves in determining the early vasoconstrictor response to local cooling in the leg and forearm.

The reduced vasoconstriction with adrenoceptors antagonism in the present data confirms the previously observed role of the noradrenergic nerves in the late vasoconstrictor response to local cooling (Johnson et al. 2005; ThompsonTorgerson et al. 2007; Hodges et al. 2007b; Yamazaki 2012). Our findings demonstrated greater noradrenergic involvement in the vasoconstrictor response to local cooling (30 min at $24^{\circ} \mathrm{C}$ ) at the leg than at the forearm skin sites. Also, Yamazaki and Yuge (2011) found higher vasoconstriction in the leg than in the arm in response to administration of exogenous norepinephrine, suggesting higher sensitivity of $\alpha_{1^{-}}$, and $\alpha_{2^{-}}$adrenoceptors in the leg. In contrast, cutaneous vasoconstriction in the leg and arm was similar at all concentrations of exogenous norepinephrine infusion in men and women (Greaney et al. 2014). Opposite to the preceding proposition, this suggests similar adrenergic responsiveness between the upper and lower body regions. This discrepancy might be due to methodological differences between the studies. In the study of Greaney et al. (2014), norepinephrine was dissolved with ascorbic acid, which extended the half-life of the drug from $8.5 \mathrm{~min}$ to $180 \mathrm{~min}$, and the doses concentrations were from $10^{-12}$ to $10^{-2} \mathrm{M}$, compared to the study of Yamazaki and Yuke (2011) who infused norepinephrine without ascorbic acid with concentrations from $10^{-8}$ to $10^{-2} \mathrm{M}$. A vasodilation rather than vasoconstriction was induced with norepinephrine doses lower than $10^{-8} \mathrm{M}$ (Greaney et al. 2014). These methodological differences and their associated responses might have altered the limbs adrenergic responsiveness with higher norepinephrine concentrations.

A further conflicting finding, Del Pozzi and Hodges (2015) unpredictably found less noradrenergic contribution in the leg than in the forearm during skin local heating at $42^{\circ} \mathrm{C}$ for $35 \mathrm{~min}$. The different types of stimuli which found greater noradrenergic contribution in the leg than the arm such as local cooling (as in the present study), reflex stimuli (Rusch et al. 1981; Vissing et al. 1989; Yamazaki et al. 2006a), and/or $\alpha$-adrenoceptor agonists (Yamazaki and Yuge 2011) might have differentially impacted the expression of adrenergic receptors compared to local heating and the subsequent responses. For example, the vasoconstrictor response to local cooling appears to depend on the translocation of $a_{2 c}$-adrenoceptors to the cell membrane (Bailey et al. 2004), with no important role for the neuropeptide Y (NPY) receptors (Johnson et al. 2005), while during local heating noradrenergic and NPY receptors appear to equally contribute in the cutaneous vasodilator response (Hodges et al. 2008). Moreover, peripheral vasodilation has been at- tributed particularly to the activation of $\beta_{1}$-adrenoceptors since their blockade resulted in complete reversion of norepinephrine-induced vasodilation (Vatner et al. 1985). In addition, infusion of $\beta$-adrenoceptor agonist evoked greater $\beta$-mediated vasodilation in the arm compared to the leg, suggesting heterogeneity of $\beta$-receptors sensitivity (Jacob et al. 2000; Yamazaki and Yuge 2011). Consequently, the sensitivity of $\beta$-adrenoceptors and/or NPY receptors might have played a role in the higher noradrenergic contribution observed in the forearm during local heating (Del Pozzi and Hodges 2015), compared to local cooling during which the $\alpha_{2 c}$-adrenoceptors contribution is predominant.

Similar to our findings, CVC levels after Yoh/Prop (Johnson et al. 2005) or after BT infusion were not changed from baseline (Yamazaki et al. 2006b; Hodges et al. 2006; Hodges et al. 2007b). However, others have shown increased basal CVC with BT treatment under normal local temperature $\left(\mathrm{T}_{\text {loc }}\right)$ $\left(33^{\circ} \mathrm{C}\right)$ in the leg and forearm (Del Pozzi and Hodges 2015). In terms of limb comparisons, some studies have agreed with our findings in which basal CVC was similar between the leg and forearm prior to local heating (Hodges et al. 2015) and prior to administration of adrenergic agonists (Yamazaki and Yuge 2011; Greaney et al. 2014). On the other hand, others have shown higher basal CVC in the leg than in the forearm at control and at BT-treated sites when $\mathrm{T}_{\text {loc }}$ was set at $33^{\circ} \mathrm{C}$ (Del Pozzi et al. 2013; Del Pozzi and Hodges 2015). These conflicts might be related to the different methodologies used by the studies. For instance, while BT was applied via microdialysis in this study and the study of Del Pozzi and Hodges (2015); others used iontophoresis to apply BT into the skin (Johnson et al. 2005; Yamazaki et al. 2006b). In the present study Yoh/Prop (5 $\mathrm{mM}$ and $1 \mathrm{mM}$, respectively) was infused within $60 \mathrm{~min}$ while $\mathrm{T}_{\text {loc }}$ was stabilized at $34^{\circ} \mathrm{C}$, whereas in the study of Del Pozzi and Hodges (2015) BT (10 $\mathrm{mM}$ ) was administered within $30 \mathrm{~min}$ at a $\mathrm{T}_{\mathrm{loc}}$ of $33^{\circ} \mathrm{C}$ at the time of basal measurements. Also, the different levels of the subjects' heat acclimatization might have contributed to the conflicting results of basal CVC.

The whole body skin and core temperatures were not measured, and this is a major limitation of this study. Whole body temperatures relative to the local temperature have been found influential on the local SkBF (Wilson et al. 2002). In addition, the level of exercise training of the participants was not taken in consideration. There was a possibility that the training status might have impacted the results since exercise training was shown to modify the cutaneous vascular responses in terms of core temperature threshold at which local SkBF starts to rise (Roberts et al. 1977) and the magnitude of the vascular conductance at a certain level of body temperature (Takeno et al. 2001). Nonetheless, the effect of exercise training on the vasoconstrictor response to local cooling has not been investigated yet. Furthermore, antagonism of the noradrenergic receptors in this study 
excluded the role of the other co-transmitter receptor, i.e. NPY receptors, in the regional vasoconstrictor response to local cooling. In fact, blocking the NPY receptors in the forearm skin resulted in similar initial and late vasoconstrictor responses to local cooling with control sites, suggesting no important role for these receptors (Johnson et al. 2005). However, it is still warranted to examine their contribution in other body regions.

In conclusion, these data indicate that the leg skin demonstrated a higher vasoconstrictor response to the late phase of local cooling than the forearm. Due to the abolished differences in CVC with adrenergic receptors antagonism it appears that the heterogeneous responses to local cooling are probably in part due to a higher noradrenergic contribution in the leg than in the forearm.

Acknowledgements. We thank all the participants who committed their time to be part of the study. We also thank Dr. Gary Hodges for helping with data collection, and for providing guidelines to enhance the procedures of the study.

\section{References}

Bailey SR, Eid AH, Mitra S, Flavahan S, Flavahan NA (2004): Rho kinase mediates cold-induced constriction of cutaneous arteries: role of alpha2C-adrenoceptor translocation. Circ. Res. 94, 1367-1374

https://doi.org/10.1161/01.RES.0000128407.45014.58

Boels PJ, Verbeuren TJ, Vanhoutte PM (1985): Moderate cooling depresses the accumulation and the release of newly synthesized catecholamines in isolated canine saphenous veins. Experientia 41, 1374-1377 https://doi.org/10.1007/BF01949995

Carter SJ, Hodges GJ (2011): Sensory and sympathetic nerve contributions to the cutaneous vasodilator response from a noxious heat stimulus. Exp. Physiol. 96,1208-1217 https://doi.org/10.1113/expphysiol.2011.059907

Charkoudian N, Stephens DP, Pirkle KC, Kosiba WA, Johnson JM (1999): Influence of female reproductive hormones on local thermal control of skin blood flow. J. Appl. Physiol. 87, 1719-1723

Chotani MA, Flavahan S, Mitra S, Daunt D, Flavahan NA(2000): Silent alpha(2C)-adrenergic receptors enable cold-induced vasoconstriction in cutaneous arteries. Am. J. Physiol. Heart Circ. Physiol. 278, H1075-1083

Chotani MA, Mitra S, Su BY, Flavahan S, Eid AH, Clark KR, Montague CR, Paris H, Handy DE, Flavahan NA (2004): Regulation of alpha(2)-adrenoceptors in human vascular smooth muscle cells. Am. J. Physiol. Heart Circ. Physiol. 286, H59-67

Crandall CG, Shibasaki M, Yen TC (2002): Evidence that the human cutaneous venoarteriolar response is not mediated by adrenergic mechanisms. J. Physiol. 538, 599-605 https://doi.org/10.1113/jphysiol.2001.013060

Del Pozzi AT, Carter SJ, Collins AB, Hodges GJ (2013): The regional differences in the contribution of nitric oxide synthase to skin blood flow at forearm and lower leg sites in response to local skin warming. Microvasc. Res. 90, 106-111 https://doi.org/10.1016/j.mvr.2013.10.003

Del Pozzi AT, Hodges GJ (2015): Comparison of the noradrenergic sympathetic nerve contribution during local skin heating at forearm and leg sites in humans. Eur. J. Appl. Physiol. 115, $1155-1164$

https://doi.org/10.1007/s00421-014-3097-1

Greaney JL, Stanhewicz AE, Kenney WL, Alexander LM (2014): Lack of limb or sex differences in the cutaneous vascular responses to exogenous norepinephrine. J. Appl. Physiol. 117, $1417-1423$ https://doi.org/10.1152/japplphysiol.00575.2014

Hertzman AB, Randall WC (1948): Regional differences in the basal and maximal rates of blood flow in the skin. J. Appl. Physiol. 1, 234-241

Hodges GJ, Zhao K, Kosiba WA, Johnson JM (2006): The involvement of nitric oxide in the cutaneous vasoconstrictor response to local cooling in humans. J. Physiol. 574, 849-857 https://doi.org/10.1113/jphysiol.2006.109884

Hodges GJ, Kosiba WA, Zhao K, Alvarez GE, Johnson JM (2007a): The role of baseline in the cutaneous vasoconstrictor responses during combined local and whole body cooling in humans. Am. J. Physiol. Heart Circ. Physiol. 293, H3187-3192 https://doi.org/10.1152/ajpheart.00815.2007

Hodges GJ, Traeger JA, Tang T, Kosiba WA, Zhao K, Johnson JM (2007b): Role of sensory nerves in the cutaneous vasoconstrictor response to local cooling in humans. Am. J. Physiol. Heart Circ. Physiol. 293, H784-789 https://doi.org/10.1152/ajpheart.00323.2007

Hodges GJ, Kosiba WA, Zhao K, Johnson JM (2008): The involvement of norepinephrine, neuropeptide $\mathrm{Y}$, and nitric oxide in the cutaneous vasodilator response to local heating in humans. J. Appl. Physiol. 105, 233-240 https://doi.org/10.1152/japplphysiol.90412.2008

Hodges GJ, Johnson JM (2009): Adrenergic control of the human cutaneous circulation. Appl. Physiol. Nutr. Metab. 34, 829-839 https://doi.org/10.1139/H09-076

Hodges GJ, Chiu C, Kosiba WA, Zhao K, Johnson JM (2009a): The effect of microdialysis needle trauma on cutaneous vascular responses in humans. J. Appl. Physiol. 106, 1112-1118 https://doi.org/10.1152/japplphysiol.91508.2008

Hodges GJ, Kosiba WA, Zhao K, Johnson JM (2009b): The involvement of heating rate and vasoconstrictor nerves in the cutaneous vasodilator response to skin warming. Am. J. Physiol. Heart Circ. Physiol. 296, H51-56 https://doi.org/10.1152/ajpheart.00919.2008

Hodges GJ, Del Pozzi AT, McGarr GW, Mallette MM, Cheung SS (2015): The contribution of sensory nerves to cutaneous vasodilatation of the forearm and leg to local skin heating. Eur. J. Appl. Physiol. 115, 2091-2098 https://doi.org/10.1007/s00421-015-3188-7

Jacob G, Costa F, Shannon J, Robertson D, Biaggioni I (2000): Dissociation between neural and vascular responses to sympathetic stimulation: contribution of local adrenergic receptor function. Hypertension 35, 76-81 https://doi.org/10.1161/01.HYP.35.1.76 
Johnson JM (1990):The cutaneous circulation. In: Laser-Doppler Blood Flowmetry. (Eds. Shepherd AP, Öberg PA), New York, Springer, pp 121-139 https://doi.org/10.1007/978-1-4757-2083-9_8

Johnson JM, Yen TC, Zhao K, Kosiba WA (2005): Sympathetic, sensory, and nonneuronal contributions to the cutaneous vasoconstrictor response to local cooling. Am. J. Physiol. Heart Circ. Physiol. 288, H1573-1579 https://doi.org/10.1152/ajpheart.00849.2004

Johnson JM, Minson CT, Kellogg DL (2014): Cutaneous vasodilator and vasoconstrictor mechanisms in temperature regulation. Compr. Physiol. 4, 33-89 https://doi.org/10.1002/cphy.c130015

Kubli S, Waeber B, Dalle-Ave A, Feihl F (2000): Reproducibility of laser Doppler imaging of skin blood flow as a tool to assess endothelial function. J. Cardiovasc. Pharmacol. 36, 640-648 https://doi.org/10.1097/00005344-200011000-00014

Oberg P (1990): Laser-Doppler flowmetry. Crit. Rev. Biomed. Eng. $18,125-163$

Park MK, Guntheroth WG (1970): Direct blood pressure measurements in brachial and femoral arteries in children. Circulation 41, 231-237 https://doi.org/10.1161/01.CIR.41.2.231

Pawelczyk JA, Levine BD (2002): Heterogeneous responses of human limbs to infused adrenergic agonists: a gravitational effect? J. Appl. Physiol. 92, 2105-2113 https://doi.org/10.1152/japplphysiol.00979.2001

Pérgola PE, Kellogg DL, Johnson JM, Kosiba WA, Solomon DE (1993): Role of sympathetic nerves in the vascular effects of local temperature in human forearm skin. Am. J. Physiol. 265, H785-792

Petrofsky JS, McLellan K, Prowse M, Bains G, Berk L, Lee S (2010): The effect of body fat, aging, and diabetes on vertical and shear pressure in and under a waist belt and its effect on skin blood flow. Diabetes Technol. Ther. 12, 153-160 https://doi.org/10.1089/dia.2009.0123

Roberts MF, Wenger CB, Stolwijk JA, Nadel ER (1977): Skin blood flow and sweating changes following exercise training and heat acclimation. J. Appl. Physiol. 43, 133-137

Rusch NJ, Shepherd JT, Webb RC, Vanhoutte PM (1981): Different behavior of the resistance vessels of the human calf and forearm during contralateral isometric exercise, mental stress, and abnormal respiratory movements. Circ. Res. 48, I118-130

Saumet JL, Kellogg DL, Taylor WF, Johnson JM (1988): Cutaneous laser-Doppler flowmetry: influence of underlying muscle blood flow. J. Appl. Physiol. 65, 478-481

Stephens DP, Aoki K, Kosiba WA, Johnson JM (2001): Nonnoradrenergic mechanism of reflex cutaneous vasocon- striction in men. Am. J. Physiol. Heart Circ. Physiol. 280, H1496-1504

Takeno Y, Kamijo YI, Nose H (2001):Thermoregulatory and aerobic changes after endurance training in a hypobaric hypoxic and warm environment. J. Appl. Physiol. 91, 1520-1528

Tew GA, Saxton JM, Klonizakis M, Moss J, Ruddock AD, Hodges GJ (2011): Aging and aerobic fitness affect the contribution of noradrenergic sympathetic nerves to the rapid cutaneous vasodilator response to local heating. J. Appl. Physiol. 110, $1264-1270$

https://doi.org/10.1152/japplphysiol.01423.2010

Thompson-Torgerson CS, Holowatz LA, Flavahan NA, Kenney WL (2007): Cold-induced cutaneous vasoconstriction is mediated by Rho kinase in vivo in human skin. Am. J. Physiol. Heart Circ. Physiol. 292, H1700-1705

https://doi.org/10.1152/ajpheart.01078.2006

Vatner SF, Knight DR, Hintze TH (1985): Norepinephrine-induced beta 1-adrenergic peripheral vasodilation in conscious dogs. Am. J. Physiol. 249, H49-56

Vissing SF, Scherrer U, Victor RG (1989): Relation between sympathetic outflow and vascular resistance in the calf during perturbations in central venous pressure. Evidence for cardiopulmonary afferent regulation of calf vascular resistance in humans. Circ. Res. 65, 1710-1717 https://doi.org/10.1161/01.RES.65.6.1710

Wilson TE, Cui J, Crandall CG (2002): Effect of whole-body and local heating on cutaneous vasoconstrictor responses in humans. Auton. Neurosci. 97, 122-128 https://doi.org/10.1016/S1566-0702(02)00046-2

Yamazaki F, Nakayama Y, Sone R (2006a): Whole-body heating decreases skin vascular response to low orthostatic stress in the lower extremities. J. Physiol. Sci. 56, 157-164 https://doi.org/10.2170/physiolsci.RP000406

Yamazaki F, Sone R, Zhao K, Alvarez GE, Kosiba WA, Johnson JM (2006b): Rate dependency and role of nitric oxide in the vascular response to direct cooling in human skin. J. Appl. Physiol. 100, 42-50

https://doi.org/10.1152/japplphysiol.00139.2005

Yamazaki F, Yuge N (2011): Limb-specific differences in the skin vascular responsiveness to adrenergic agonists. J. Appl. Physiol. 111, 170-176 https://doi.org/10.1152/japplphysiol.00068.2011

Yamazaki F (2012): Oral vitamin C enhances the adrenergic vasoconstrictor response to local cooling in human skin. J. Appl. Physiol. 112, 1689-1697 https://doi.org/10.1152/japplphysiol.00043.2012

Received: March 28, 2017

Final version accepted: June 9, 2017 